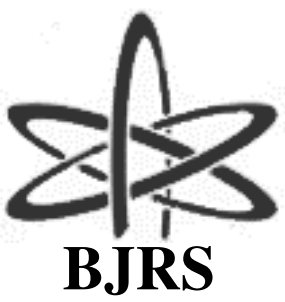

BRAZILIAN JOURNAL

$\mathrm{OF}$

RADIATION SCIENCES

03-1A (2015) 01-10

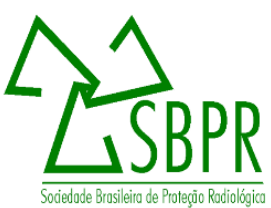

\title{
Estudo in vitro dos efeitos da radiofrequência gerada por plasmas em células neoplásicas HT-29
}

\author{
D. Andrighetto ${ }^{1}$, E. B. Dornelles², I. B. M. da Cruz ${ }^{3}$ e E. Lüdke \\ ${ }^{1}$ CCNE-Departamento de Fìsica (CCNE-DEFIS), Universidade Federal de Santa Maria (UFSM) \\ Campus Universitário, 97150-900, Santa Maria-RS, Brasil \\ daniela.andrighetto@hotmail.com \\ ${ }^{2}$ Laboratório de Biogenômica/Departamento de Morfologia, Universidade Federal de Santa Maria (UFSM) \\ Campus Universitário, 97150-900, Santa Maria-RS, Brasil \\ dornellesedu@gmail.com \\ ${ }^{3}$ Programa de Pós-Graduação em Farmacologia, Universidade Federal de Santa Maria (UFSM) \\ Campus Universitário, 97150-900, Santa Maria-RS, Brasil \\ ibmcruz@hotmail.com \\ ${ }^{4}$ CCNE-Departamento de Fìsica (CCNE-DEFIS), Universidade Federal de Santa Maria (UFSM) \\ Campus Universitário, 97150-900, Santa Maria-RS, Brasil \\ evertonludke@gmail.com
}

\section{RESUMO}

$\mathrm{Na}$ literatura recente, é de particular importância o estudo de alterações bioquímicas provocadas pela exposição de células in vitro sobre a ação de campos elétricos e magnéticos oscilantes em baixas frequências abaixo de MHz. Em particular, autores têm ressalvado a possibilidade da técnica PEFT ("Plasma Emission Field Treatment") como adjuvante para terapias antineoplásica pelo possível efeito antiproliferativo no mecanismo de divisão celular. O objetivo, então é desenvolver um sistema de irradiação de células in vitro com intensidades controláveis de radiação em $27 \mathrm{MHz}$ produzida por uma coluna de plasma de argônio com modulação em amplitude variável na faixa de $100-700 \mathrm{kHz}$. Neste trabalho apresenta-se e discute-se um experimento proposto para esse fim, com análise de toxicidade (DNA Picogreen®) e viabilidade (MTT) celular induzida pela radiação em células de linhagem HT-29 (adenocarcinoma de cólon). Os dados permitem observar que efeitos de toxicidade celular podem ocorrer com exposição a campos produzidos por plasma de argônio com intensidades na ordem de pelo menos 3,2 $\mathrm{W} / \mathrm{cm}^{2}$ e tempos de exposição acima de 3,5 horas em modo contínuo. Uma análise das populações celulares para testes de toxicidade celular empregando o teste-t de Student não mostram alterações significativas $(p<0,05)$ na quantidade de DNA liberado pela ação da radiofrequência, embora se verificou que a viabilidade celular (MTT) não seja significativamente alterada por longas exposições a radiação de plasma induzida por sinais de radiofrequência 
em $27 \mathrm{MHz}(\mathrm{p}>0,34)$. Efeitos citotóxicos devido à destruição de parede celular pelo aquecimento das amostras não foram detectados em nenhum dos ensaios realizados.

Palavras-chave: alterações bioquímicas, células neoplásicas e radiação.

\section{INTRODUÇÃO}

Os efeitos deletérios de radiações ionizantes na proliferação de células neoplásicas por meio da produção de radicais livres ou destruição direta de DNA [1] são bem conhecidos na literatura médica, sendo consolidada a disciplina de Radioterapia Médica como técnica de combate a doenças neoplásicas [2,3]. Entretanto, historicamente há evidências de retardo na progressão de certos tipos de doenças como o câncer de ovário pela aplicação de altas intensidades de radiações não ionizantes [4] em comprimentos de onda decamétricos (12-30 MHz) na forma de diatermia de ondas curtas. Desde o século passado, tem-se atribuído à diatermia por ondas curtas os efeitos de retardo na proliferação celular como na aceleração do metabolismo de células normais [5] comprovando o efeito celular pela aplicação de ondas eletromagnéticas na faixa de radiofrequência (20-900 MHz).

$\mathrm{Na}$ literatura recente [6,7], é de particular importância o estudo de identificação de alterações bioquímicas provocadas pela exposição de células in vitro sobre a ação de campos elétricos e magnéticos oscilantes em baixas frequências abaixo de $100 \mathrm{MHz}$. Como exemplo importante, temos resultados experimentais sobre a possibilidade da técnica PEFT ("Plasma Emission Field Treatment") como adjuvante para terapias antineoplásicas com drogas-alvo pelo possível efeito antiproliferativo no mecanismo de divisão celular [8]. De fato, diversos autores têm argumentado sobre a ocorrência da gênese neoplásica devido à exposição prolongada de tecidos humanos a fontes de microondas de baixa potência e o assunto sobre estabelecimento de limites dosimétricos de risco e benefício de radiações não-ionizantes para o ser humano ainda permanece controverso. 
Considerando essa motivação, é apresentado nesse trabalho um sistema de irradiação de células in vitro com intensidades controláveis de radiação em $27 \mathrm{MHz}$ produzida por uma coluna de plasma de argônio com modulação em amplitude variável na faixa de 100-700 kHz e uma câmara que consiste em uma coluna de plasma de argônio para exposição de amostras celulares.

Relata-se e discute-se, portanto, resultados preliminares sobre os efeitos de exposição variada de radiação não-ionizante para amostras de leucócitos e células de linhagem HT-29 de adenocarcinoma de cólon [9] a fim de fomentar discussões sobre os limites dosimétricos de segurança dessa categoria de radiação.

\section{MATERIAIS E MÉTODOS}

A metodologia do presente trabalho consiste na descrição de um sistema alimentador de plasma de argônio e de testes de exposição de uma amostra de células leucocitárias humanas de células HT-29 (adenocarcinoma de cólon) com uso de testes de função celular padrão em estudos de bioquímica celular.

\subsection{O Sistema Gerador de Plasma}

Como sistema gerador de plasma, utilizou-se um oscilador de modulação variável capaz de produzir onda contínua ou pulsos em banda lateral singela (SSB) de frequência variável entre 100 e 300 kHz. Os sinais de modulação SSB são produzidos por um gerador de funções digital para testar possíveis efeitos de compressão mecânica pela modulação do sinal na excitação de estruturas internas celulares como microtúbulos ou paredes de compartimentos intracelulares, o que acredita-se ser devido a indução de ondas acústicas e sônicas nas organelas induzidas pelos pulsos de radiofrequência.

Como frequência portadora, foram implementados osciladores internos nas frequências de 13,56 $\mathrm{MHz}$ e 27,12 MHz por serem frequências reservadas para experimentos de excitação de colunas 
de plasma de diferentes gases em laboratórios de física de plasmas. Osciladores a cristal tipo Clapp modificado empregando válvulas tríodo ECC83 fornecem cerca de $6 \mathrm{~W}$ de potência de radiofrequência que alimenta duas válvulas tipo pêntodo de potência tipo 6146B ou QE05/40 conforme mostra a Fig. 1.

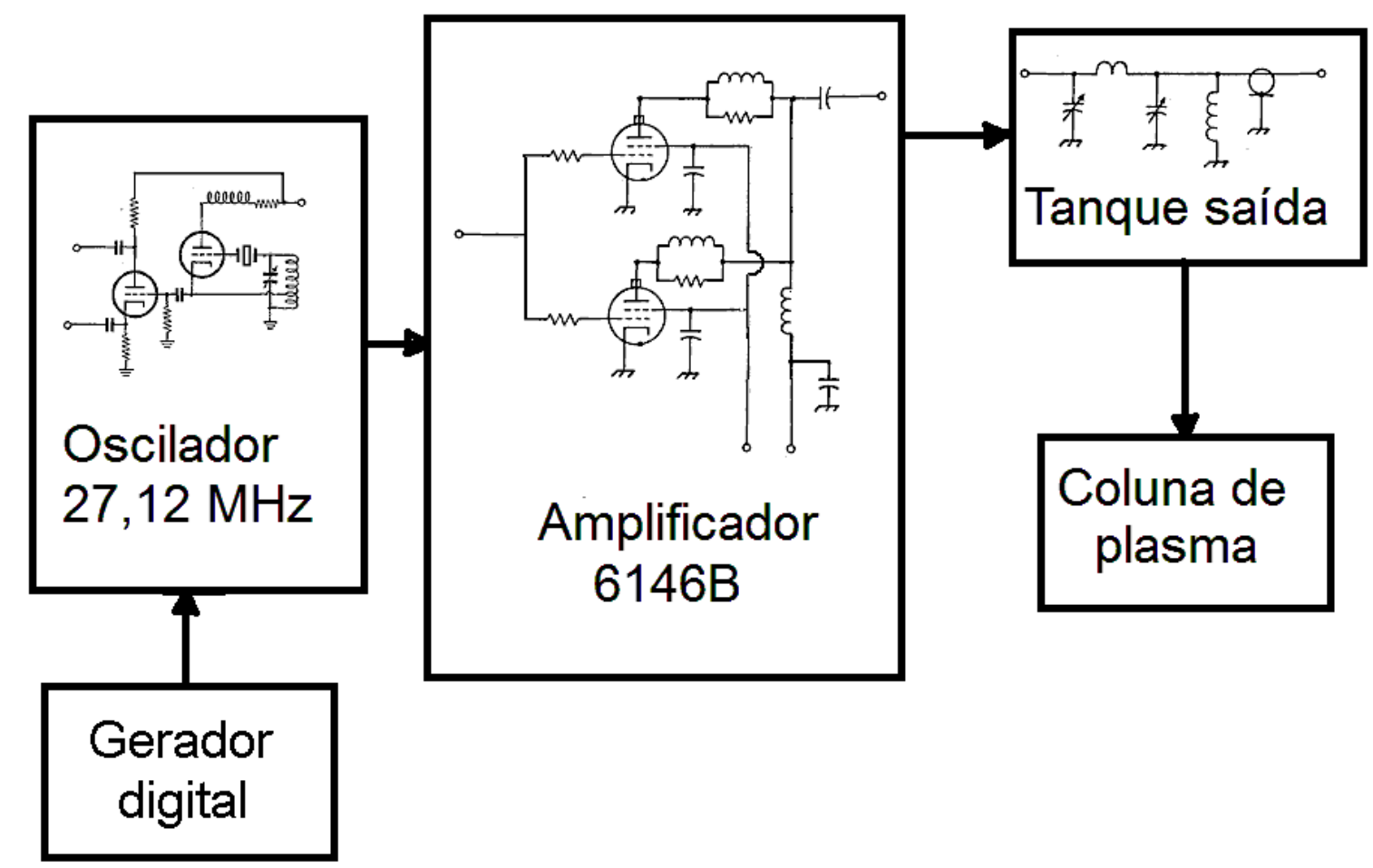

Figura 1. Diagrama ilustrativo dos blocos de circuito do gerador de radiofrequência modulado para excitação da coluna de plasma de argônio que produz a radiação nãoionizante de polarização aleatória.

O sinal modulado ou de onda continua (C.W.) é injetado na grade de controle dos pêntodos e na saída temos uma rede de casamento de impedâncias. Para casamento de impedâncias entre as placas das válvulas e a coluna de plasma, empregou-se um circuito tanque de acoplamento tipo $\pi$ compreendido por um indutor-série de alta corrente com $112 \mathrm{nH}$ de indutância e dois capacitores variáveis de alta voltagem para fazer a sintonia do casamento de impedâncias. Uma fonte de 
alimentação de baixo "ripple" com 450 V, 2A alimenta o circuito e uma derivação de corrente alternada de 6,3 V, 6 A alimenta o filamento das válvulas.

Como antena de radiofrequência, foi confeccionada uma coluna de plasma de argônio de paredes de vidro com $12 \mathrm{~cm}$ de comprimento por $2 \mathrm{~cm}$ de espessura, conectada na saída do gerador/excitador por meio de um resistor limitador de corrente tipo "ballast" com 4,7 k $\Omega$ e 25 W. O interior da coluna consiste em argônio a uma pressão interna do gás de cerca de 0,1 mmHg. Em plena excitação, estima-se uma densidade de íons de argônio na ordem de $10^{11} \mathrm{~cm}^{-3}$. A amplitude do sinal bobina censora de quatro espiras a $20 \mathrm{~cm}$ da coluna é monitorada para controle de sintonia e nível de potência. Os sinais são transportados pelo gerador à coluna de plasma através de um cabo RG-213 de $50 \Omega$ de impedância.

Para o experimento em modo C.W. o circuito tanque foi ajustado para a máxima potência e um medidor de onda estacionária entre o gerador e a linha de transmissão que alimenta a coluna de plasma possibilita medir cerca de $108 \mathrm{~W}$ e razão de onda estacionária (R.O.E.) menor que $2 \%$ para a alimentação em $27,12 \mathrm{MHz}$, correspondendo a uma intensidade teórica a $5 \mathrm{~cm}$ da coluna, ajustáveis no intervalo de $0,5-6,4 \mathrm{~W} / \mathrm{cm}^{2}$ e tempos de exposição variáveis onde se assume produção com polarização randômica pela coluna de plasma.

O uso de tubos a vácuo foi a melhor escolha, pois possibilita a obtenção de boa estabilidade de potência e frequência por longas horas de ensaios, além de robustez necessária para os trabalhos de irradiação.

Uma câmara tipo gaiola de Faraday de alumínio, ventilada, foi empregada para evitar interferência em equipamentos próximos e a temperatura na vizinhança das amostras se manteve estável entre $22-32,8{ }^{\circ} \mathrm{C}$ durante os ensaios, evitando dano térmico às amostras de cultivo celulares. 


\subsection{Procedimento experimental}

O procedimento experimental metodológico consistiu em expor amostras de leucócitos de células HT-29 de adenocarcinoma de cólon a uma distância de $5 \mathrm{~cm}$ da coluna de plasma, dentro da gaiola de Faraday a temperatura ambiente. Foram empregados dois intervalos de tempo de 1 hora a 7 horas de exposição à radiação C.W. em 27,12 MHz nas condições dosimétricas experimentais descritas na seção precedente.

Os testes bioquímicos realizados fora a análise de toxicidade celular pelo meio da identificação de DNA dupla-fita extracelular (DNA Picogreen®) [10], a ocorrência de espécies reativas de oxigênio e peroxidonitritos pela técnica da diclorofluoresceína (DFH_DA) [11] e o teste de viabilidade celular ensaio colorimétrico com 3-(4,5-dimetiltiazol-2yl)-2,5-difenil brometo de tetrazolina (MTT) [12].

A determinação quantitativa da redução de MTT por enzimas mitocondriais celulares constitui um método colorimétrico simples para avaliar a viabilidade da respiração celular, uma vez que a espectrofotometria permite identificar a magnitude da redução MTT pelas desidrogenasses mitocondriais e, portanto, serve como ferramenta avaliadora qualitativa da produção de radicais oxidativos pela ação da radiação não-ionizante.

\section{RESULTADOS E DISCUSSÕES}

A Figura 2 ilustra os resultados da análise dessas provas celulares após um dos ensaios que compreendeu um tempo de exposição de 5 horas. 

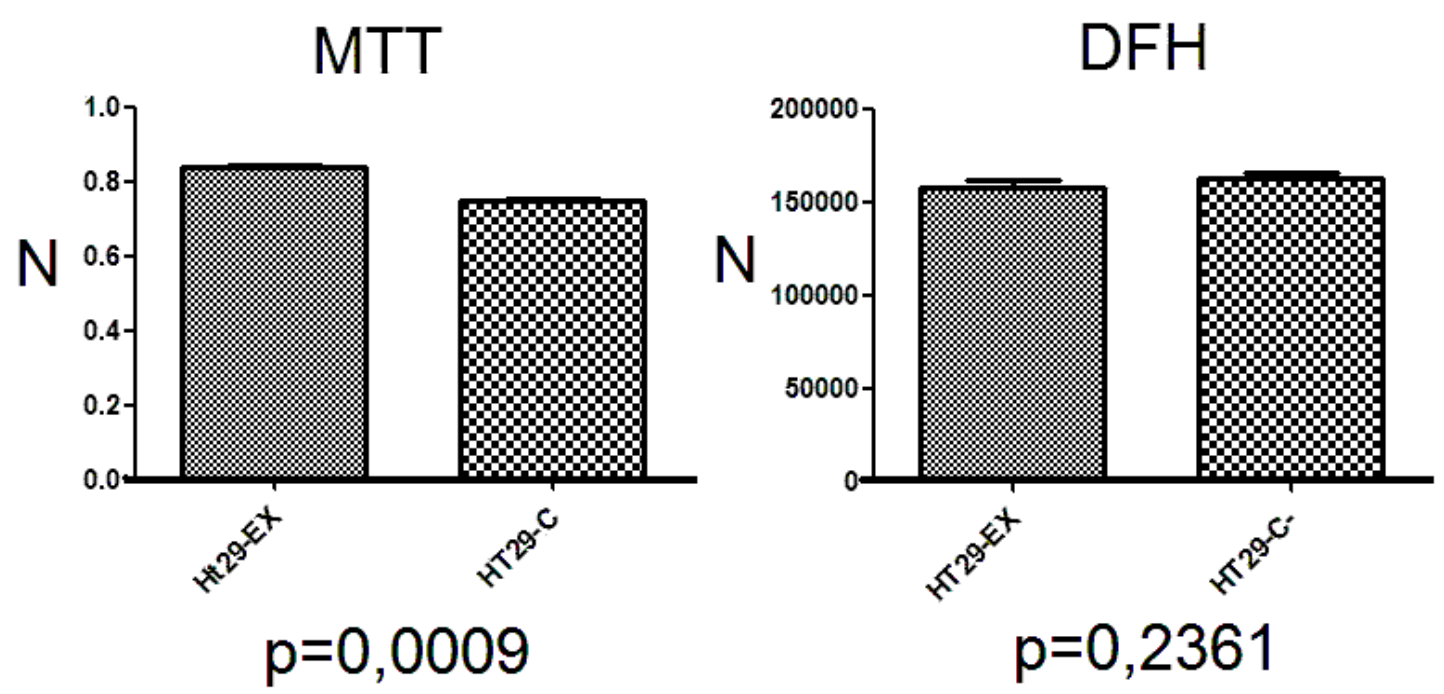

\section{Picogreen}

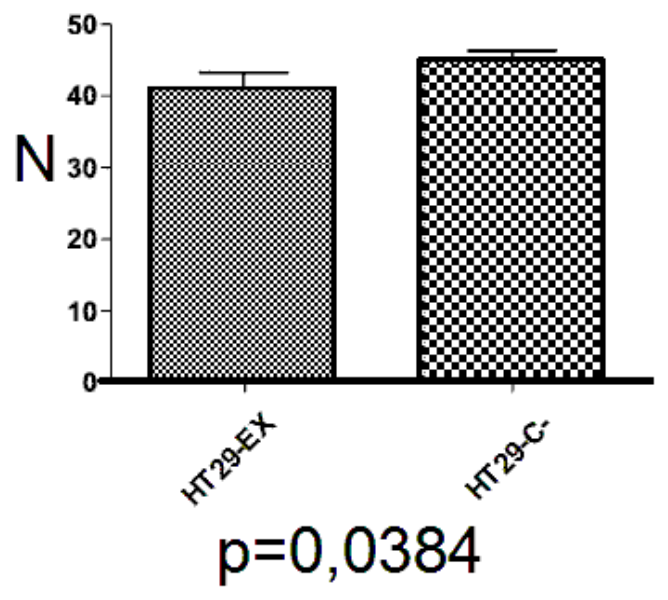

Figura 2. Resultados das análises bioquímicas para um tempo de exposição de 5 horas para uma amostra de células de linhagem HT-2. Em que N é o número de células, HT29EX são as células expostas e HT29-C, as células controle.

A Figura 2 também informa as probabilidades de obtenção de diferenças entre grupos de amostras irradiadas e não irradiadas, usando o teste $t$ de Student. A análise das populações 
celulares para testes de toxicidade celular, portanto, indicam alterações na função mitocondrial, mas não se detectam extravasamento de DNA de dupla fita para o meio extracelular com os níveis de campos eletromagnéticos empregados.

Entretanto, percebeu-se que períodos de exposição inferiores a três horas na dosagem de radiação estimada para o equipamento não produzem alterações celulares nos testes efetuados, sendo necessários pelo menos 4 horas de exposição para detecção de diferenças estatisticamente significativas nos ensaios seguindo a nossa metodologia.

Para células leucocitárias obtidas de indivíduos saudáveis, não foi detectado quaisquer forma de dano celular com os testes empregados.

\section{CONCLUSÕES}

Nesse trabalho, é apresentado os resultados sobre o desenvolvido um sistema de geração de radiação de plasma de argônio de potência intermediária para estudos de radiações nãoionizantes sobre amostras de culturas celulares para células de adenocarcinoma de cólon.

Os resultados de medições relatadas nesse experimento possibilitam determinar as condições mínimas de dosimetria de radiações ionizantes que podem provocar alterações celulares detectáveis pelos exames bioquímicos padrão para análise de células in vitro.

Os dados coletados permitiram observar que efeitos de toxicidade celular podem ocorrer com exposição a campos produzidos por plasma de argônio com intensidades na ordem de pelo menos 3,2 W/cm ${ }^{2}$ e tempos de exposição acima de 5 horas em modo contínuo (C.W.), requerendo tempos de exposição maiores para modo pulsado. 
Efeitos citotóxicos devido à destruição de parede celular pelo aquecimento das amostras não foram detectados em nenhum dos ensaios realizados, independente da qualidade da modulação de sinal empregado, o que sugere que os valores dosimétricos apontados nesse artigo estão no limite de segurança para radiações eletromagnéticas de comprimentos de ondas curtas. 


\section{REFERÊNCIAS}

1. J. Kiefer, Biological Radiation Effects, Springer-Verlag, Heidelberg, Alemanha (1990)

2. S. Forshier, Essentials of Radiation, Biology and Protection, Cengage Learning, New York EUA (2008)

3. E.C. Halperin, D.E. Wazer, C.A. Perez, L.W. Brady, Perez \& Brady's Principles of Radiation Oncology, LWW Books, New York EUA (2013)

4. E. Schliephake, Short Wave Therapy: The Medical Uses of Electrical High Frequencies, The Actinic Press, London (1935)

5. G. P. Yen-Patton, W.F. Patton, D.M. Beer, B.S. Jacobson, "Endothelial cell response to pulsed electromagnetic fields: stimulation of growth rate and angiogenesis in vitro," ", J. Cell Physiol., 134(1), pp.37--46 (1988)

6. M. Roosli, Epidemiology of Electromagnetic Fields, CRC Press, Philadelphia, EUA (2014)

7. J.C. Lin, Electromagnetic Fields in Biological Systems, CRC Press, Philadelphia, EUA (2011)

8. J.W. Zimmerman, M.J. Pennison, I. Brezovich, N. Yi, C.T. Yang, R. Ramaker, D. Absher, R.M. Myers, N. Kuster, F.P. Costa, A. Barbault, B. Pasche, "Cancer cell proliferation is inhibited by specific modulation frequencies," British Journal of Cancer., 106(1), pp.307-$313(2012)$

9. T.R. Chen, D. Drabkowski, R.J. hay, M.Macy, W. Peterson Jr., "WiDr is a derivative of another colon adenocarcinoma cell line HT-29," Cancer Genet. Cytogenet., 27, pp.125-134 (1987)

10. R. P. Haugland, Handbook of Fluorescent Probes and Research, Molecular Probes, Inc, Eugene - OR, EUA (2001)

11. A. Aranda, L. Sequedo, L. Tolosa, G. Quintas, E. Burello, J.V. Castell, L. Gombeau, "Dicholro-dihydro-fluorescein diacetate (DCFH_DA) assay: a quantitative method for oxidative stress assessment of nanopaticle-treated cells," Toxicol. In Vitro, 27(2), pp.954-963 (2013)

12. T. Mosmann, "Rapid colorimetric assay for cellular growth and survival application to proliferation and cytotoxicity assays," Journal of Immunological 